\title{
Osmolality Measurement
}

National Cancer Institute

\section{Source}

National Cancer Institute. Osmolality Measurement. NCI Thesaurus. Code C74801.

The determination of the osmoles of solute per kilogram of solvent present in a sample. 